\title{
Simultaneous Quantitative Determination of Different Ceramide and Diacylglycerol Species in Cultured Cells by Using Liquid Chromatography-Electrospray Tandem Mass Spectrometry
}

\author{
Anna Somogyi ${ }^{1}$, Mária Berinkeiné Donkó², Farkas Sarnyai ${ }^{1}$, Gergely Becskereki², Miklós Csala', \\ Blanka Tóth ${ }^{*}$ \\ 1 Department of Medical Chemistry, Molecular Biology and Pathobiochemistry, Faculty of Medicine, Semmelweis University, \\ H-1428 Budapest, P.O.B. 2, Hungary \\ ${ }^{2}$ Department of Inorganic and Analytical Chemistry, Faculty of Chemical Technology and Biotechnology, Budapest University of \\ Technology and Economics, H-1521 Budapest, P.O.B. 91, Hungary \\ * Corresponding author, e-mail: tblanka@mail.bme.hu
}

Received: 05 December 2019, Accepted: 13 March 2020, Published online: 09 July 2020

\begin{abstract}
A sensitive, reproducible reverse-phased high performance liquid chromatography electrospray tandem mass spectrometry (HPLCESI-MS/MS) method with simple sample preparation was developed for the simultaneous determination of a wide range of ceramides, diacylglycerols (DAGs) in cultured cells. Chromatographic separation of the compounds was achieved in a 14-minute run using a C8 column with a gradient elution by methanol and $10 \mathrm{mM}$ ammonium acetate buffer as mobile phase at a flow rate of $0.5 \mathrm{ml} / \mathrm{min}$. Various ceramides, DAGs were detected with a triple quadrupol system in multiple reaction monitoring mode, which is based on a soft positive electrospray ionization. The usual sample preparation process was shortened by the application of pure methanol for the extraction instead of the widely used methanol/chloroform mixture. C17:0 ceramide which does not occur in the cell samples, was used as an internal standard. The sample preparation process was optimized and the methodology was tested on a human hepatocarcinoma cell culture. Our results clearly showed accumulation of some ceramides and DAGs in the cells treated with BSA-conjugated palmitate for 8 hours. Since both ceramides and DAGs are important lipid intermediates and signal messengers, alteration in their cellular levels have major impact on cell functions, and thus our novel analytic method can be widely used in lipotoxicity research. The presented technique can be further developed to measure other intermediates of ceramide synthesis and other derivatives of DAGs as well.
\end{abstract}

Keywords

mass spectrometry, liquid chromatography, ceramides, glycerolipids, lipotoxicity

\section{Introduction}

Depot fat stored in the adipocytes contains fatty acids (FAs) ingested with animal fat [1] and with natural or hydrogenated plant oils [2, 3] as well as FAs synthesized endogenously in the fed state. As obesity and related diseases, such as cardiovascular diseases, insulin resistance and nonalcoholic fatty liver disease have become epidemic, there is a strong emphasis on investigating their pathology. Adipocyte hypertrophy is an indispensable component of obesity in adults, and it often leads to a local inflammation in the overgrown adipose tissue, which in turn enhances triglyceride turnover and elevates serum free fatty acid (FFA) levels [4].
Oversupply of FFAs stimulates both lipid biosynthesis and FA degradation. Deleterious effects of excessive FFAs were mainly attributed to ectopic fat deposition in various cells, such as hepatocytes [4]. However, growing evidence shows that lipotoxic oxidative and endoplasmic reticulum (ER) stress [5], inflammation and apoptosis are mostly due to fatty acyl coenzyme A (acyl-CoA) build-up and to the consequent accumulation of certain lipid intermediates in the cells. Ceramides, which are amides of a sphingosine and a FA chain, constitute the hydrophobic backbone of a wide array of sphingolipids, play an important role in signaling. 
They influence cell growth and proliferation [6] and cellular senescence [7], and cell death as they can induce apoptosis $[8,9]$. Recently, many publications have also suggested the role of ceramides in the development of insulin resistance and in $\beta$-cell failure, and thus their importance in type 2 diabetes [10]. Intracellular ceramide production (Fig. 1) is potentially affected by fatty acyl-CoA supply at different acylations in the cell. De novo synthesis of ceramides starts with the condensation of palmitoyl-CoA and serine to 3-dehydrosphinganine, and its subsequent reduction. The product, sphinganine is $N$-acylated with another acyl-CoA by ceramide synthase. Sphingosine, an intermediate of sphingolipid degradation can be recycled through $N$-acylation by sphingosine acyltransferases which can use various fatty acyl-CoA species for substrates. Diacylglycerols (DAGs) are also important lipid species with signaling functions. These compounds have two fatty acyl groups in ester bonds with two hydroxyl groups of glycerol. As it is presented in Fig. 2, they can serve as precursors in the synthesis of triacylglycerols and complex glycerophospholipids such as phosphatidylserine (PS), phosphatidylethanolamine (PE), phosphatidylcholine (PC), phosphatidylinositol (PI), etc. or galactolipids such as monogalactosyldiacylglycerol (MGDG). When 1,2-DAGs are formed by the hydrolytic cleavage of plasma membrane glycerophospholipids, mostly phosphatidylinositols by phospholipase $C$, they serve as signal messengers through the

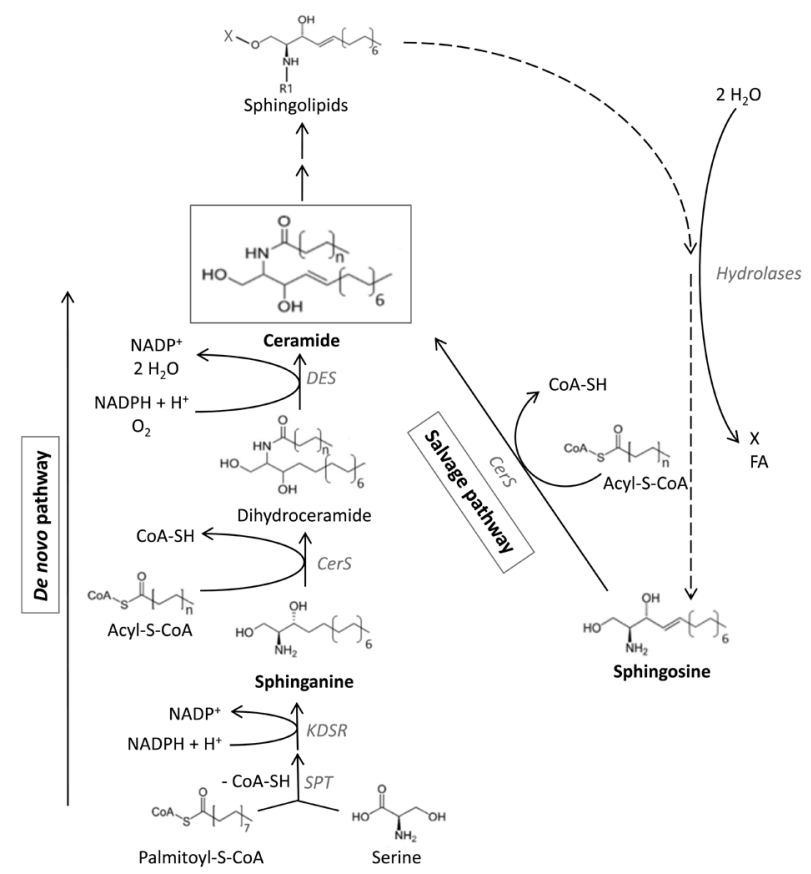

Fig. 1 De novo synthesis and salvage of ceramides. SPT: serine palmitoyl transferase, KDSR: 3-ketodihydrosphingosine reductase, CerS: ceramide synthases, DES: dihydroceramide desaturase.

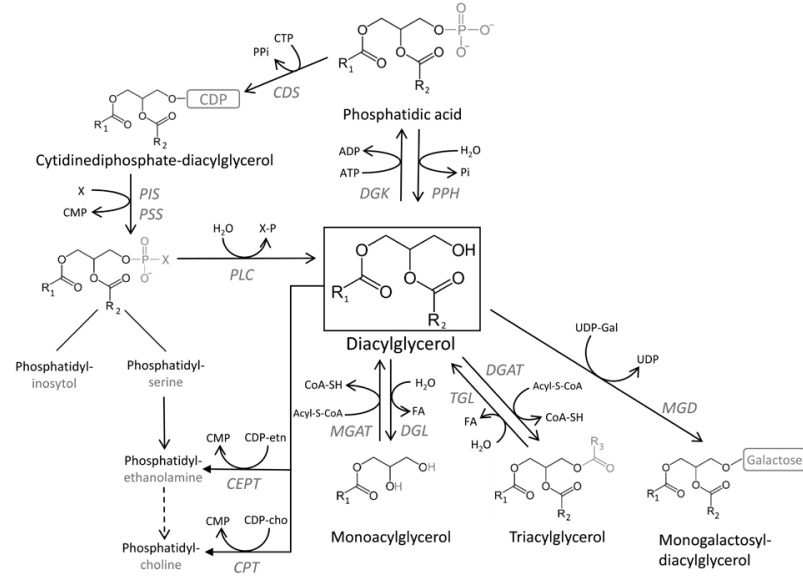

Fig. 2 Metabolism of diacylglycerols. CDS: cytidinediphosphatediacylglycerol synthase, CEPT: choline/ethanolamine phosphotransferase, CPT: choline phosphotransferase, DGK: diacylglycerol kinase, PPH: phosphatidate phosphohydrolase PI

PLC: phosphoinositide-phospholipase C, MGAT: monoacylglycerol acyltransferase, DGAT: diacylglycerol acyltransferase, DGL: diacylglycerol lipase, TGL: triacylglycerol lipase, MGD: monogalactosyl-diacyclglycerol synthase.

activation of protein kinase $\mathrm{C}$ isoenzymes [11]. DAGs also have an effect on insulin secretion in case of oversupply of FAs [12]. Since DAGs are central intermediates of phospholipid metabolism, any alteration in their structure would largely affect the composition of cellular membranes as well.

It has become evident that FA surplus exerts many of its pathologically relevant deleterious effects in the cells through the accumulation of ceramides and DAGs. Therefore, biological and medical investigations on lipotoxicity, could growingly exploit the accurate and sensitive analytical methods which are suitable for a simultaneous assessment of these two groups of lipid species.

Ceramides can be measured by different techniques, such as enzymatic measurements involving diacyglycerol kinase assay [13, 14], or chromatographic methods, such as thinlayer chromatography $[15,16]$ or high-performance liquid chromatography [17-19]. However, these methods may have limitations regarding the quantification of individual ceramide species. Tandem mass spectrometry can be a useful method to quantify different forms of ceramide simultaneously. In case of multiple reaction monitoring mode, a prior separation step is not essential as the different transitions are specific to the molecules [20-23]. However, if tandem mass spectrometry is coupled to high-performance liquid chromatography, the selectivity improves and the method is more robust since the components are separated from the impurities. An HPLC-MS/MS method was developed and used to quantify various ceramides in biological samples [23-26]. 
Measurement of DAGs was carried out by DAG kinase assay [12], capillary gas chromatography [27] and liquid chromatography coupled to mass spectrometry [28-30]. Leiker et al. used the 2,4-difluorophenyl urethane derivatives of DAGs in a normal phase separation [28] to separate 1,2-diacylglycerols and 1,3-diacylglycerols.

The main problem to be faced in case of mass spectrometry is the poor ionization ability of DAGs. To avoid this problem, derivatizing compounds, such as $N$-chlorobetainyl chloride [30] are used in the sample preparation step, alternatively ammonium acetate [28] or sodium acetate [29] buffers are added to the eluent.

We sought to develop a sensitive and reproducible HPLC-MS/MS method with a simple, chloroform-free sample preparation which is suitable for the quantitation of ceramides and DAGs in a single run. Here we demonstrate a 14-min run to separate 12 individual lipid intermediates. Our method permits the use of pure methanol as an extracting agent instead of a chloroform/methanol mixture. This method was tested analyzing the effects of palmitate treatment on ceramide and DAG levels in HepG2 human hepatocarcinoma cells.

\section{Materials and methods}

\subsection{Chemicals and reagents}

C16:0, C17:0, C18:0, C18:1(9Z) ( $>99 \%$ ceramides were purchased from Avanti Polar Lipids Inc., 1,2-dipalmitoyl-rac-glycerol (>99\%), 1-palmitoyl-2-oleoyl-sn-glycerol (>99\%), 1,2-dioleoyl-snglycerol ( $>97 \%)$, 1-octadecanoyl-2hexandecanoylsnglycerol ( $>99 \%)$, palmitic acid ( $>99 \%)$, ammonium acetate $(>98 \%)$ and bovine serum albumin (BSA) were from Sigma-Aldrich (St. Louis, MO). Methanol (gradient grade) and acetonitrile (gradient grade) were obtained from Merck. Chloroform (99.8\%) for lipid extraction was from Panreac and isopropanol was purchased from Molar Chemicals. All experiments and measurements were carried out by using Millipore ultrapure water.

\subsection{Standard solutions}

Standard stock solutions of C16:0, C18:0 and C18:1 ceramides and all DAG standards were prepared in methanol in a concentration of $5 \mu \mathrm{g} / \mathrm{ml}$ each. C17:0 ceramide was used as an internal standard in a concentration of $50 \mathrm{ng} / \mathrm{ml}$. The solutions were kept in glass vials at $20^{\circ} \mathrm{C}$.

\subsection{Cell cultures}

HepG2 human hepatocarcinoma cells were purchased from Sigma-Aldrich (St. Louis, MO) (cat. number: 850114301VL) and cultured in Minimum Essential Medium Eagle containing Earle's Salts and sodium bicarbonate, supplemented with $2 \mathrm{mM}$ L-glutamine, $1 \%$ non-essential amino acids, $10 \%$ FBS and $1 \%$ antibiotics (Thermo Scientific), at $37{ }^{\circ} \mathrm{C}$ in humidified atmosphere, containing $5 \% \mathrm{CO}_{2}$.

\subsection{Cell treatment with fatty acids}

Treatment of the cells with albumin-conjugated palmitate was based on our previous studies [31]. Briefly, before treatment, the culture medium was changed for FBS and antibiotic free medium for 1 hour. Palmitate was diluted in isopropanol to a concentration of $50 \mathrm{mM}$, conjugated with $4.16 \mathrm{mM}$ FA free BSA in 1:4 ratios, on $37^{\circ} \mathrm{C}$ for 1 hour. The working solution was always freshly prepared with FBS free and antibiotic free medium, and it contained palmitic acid at a final concentration of $250 \mu \mathrm{M}$. Cells were treated for 8 hours at $70-80 \%$ confluence in 6 -well plates.

\subsection{Sample preparation-Extraction}

At $70-80 \%$ confluence, cells were washed once with phosphate buffer (PBS), then harvested in $200 \mu$ PBS by scraping. The samples were then centrifuged in a benchtop centrifuge $\left(10 \mathrm{~min}, 1000 \mathrm{rpm}, 4{ }^{\circ} \mathrm{C}\right)$. The supernatant was removed, and the cells were suspended in $115 \mu \mathrm{l}$ PBS. $15 \mu \mathrm{l}$ of each cell suspension was removed for determination of protein concentration, and the rest was centrifuged (10 min, $1000 \mathrm{rpm}, 4{ }^{\circ} \mathrm{C}$ ). The supernatant was removed and the remaining sample was suspended in $200 \mu \mathrm{l}$ of isopropanol/methanol $(50 / 50 \mathrm{v} / \mathrm{v} \%)$, which already contained the $\mathrm{C} 17: 0$ ceramide $(50 \mathrm{ng} / \mathrm{ml})$. After this procedure, the samples were immediately frozen at $20^{\circ} \mathrm{C}$ and stored at $20^{\circ} \mathrm{C}$ until further processing.

Before the analysis, the samples were thawed at room temperature. The samples were sonicated for 15-20 sec using an ultrasonic sonotrode, then centrifuged in a benchtop centrifuge (10 min, $\left.13400 \mathrm{rpm}, 24^{\circ} \mathrm{C}\right)$. The supernatants were transferred to vials for immediate liquid chromatography tandem mass spectrometry analysis.

\subsection{Measurement of protein concentration}

Cells were washed twice with PBS, then harvested in $100 \mu \mathrm{l}$ lysis buffer by scraping. The lysis buffer contained $0.1 \%$ SDS, $5 \mathrm{mM}$ EDTA, $150 \mathrm{mM} \mathrm{NaCl}, 50 \mathrm{mM}$ Tris, $1 \%$ Tween 20, $1 \mathrm{mM} \mathrm{Na}_{3} \mathrm{VO}_{4}, 1 \mathrm{mM}$ PMSF, $10 \mathrm{mM}$ benzamidine, $20 \mathrm{mM} \mathrm{NaF}, 1 \mathrm{mM}$ pNPP and protease inhibitor cocktail. The lysates were centrifuged with benchtop centrifuge $\left(10 \mathrm{~min}, 10000 \mathrm{rpm}, 4^{\circ} \mathrm{C}\right)$. Protein concentration of the supernatant was measured with Pierce BCA Protein Kit Assay (Thermo Scientific) according to the manufacturer's recommendation, then stored at $20{ }^{\circ} \mathrm{C}$ until use. 


\subsection{Chromatographic separation}

Compounds were separated by high performance liquid chromatography using a Perkin Elmer series 200 high pressure gradient pump, autosampler, online degasser and a thermostat. A Kinetex ${ }^{\circledR} 5 \mu \mathrm{m}, \mathrm{C} 8100 \AA$, LC Column, $100 \times 3 \mathrm{~mm}$ column was used at $0.5 \mathrm{ml} / \mathrm{min}$ flow rate with a gradient elution of methanol (mobile phase A) and $10 \mathrm{mM}$ ammonium-acetate (mobile phase B): 0 min at $90 \% \mathrm{~A}$; $1 \mathrm{~min}$ at $90 \% \mathrm{~A} ; 9 \mathrm{~min}$ at $95 \% \mathrm{~A} ; 10.5 \mathrm{~min}$ at $98 \% \mathrm{~A}$; $11.5 \mathrm{~min}$ at $98 \% \mathrm{~A} ; 12 \mathrm{~min}$ at $90 \% \mathrm{~A} ; 14 \mathrm{~min}$ at $90 \% \mathrm{~A}$.

\subsection{Mass spectrometry}

Ceramide and DAG compounds were detected using a triple quadrupole mass spectrometer (Applied Biosystems MDS SCIEX 4000 Q TRAP).

The instrument was used in positive multiple reaction monitoring mode. The source parameters of the mass spectrometer are presented in Table 1. The transitions and retention times for each ceramide and DAG are shown in Table 2.

\subsection{Quantification of ceramide and diacylglycerol levels} Ceramides and DAGs were quantified by the ratios of their peak areas and of the C17:0 ceramide. This compound is a non-naturally occurring ceramide, thus it can be used as an internal standard.

\section{Results}

\subsection{Optimization of tandem mass spectrometry}

Full scan mass spectra were recorded for each ceramide and DAG standard in positive ion mode during direct infusion. Ceramides gave protonated ion spectrum, however, DAGs showed poor ionization. Thus, we added ammonium-acetate in a concentration of $10 \mathrm{mM}$ to the eluent. This way, the ammonium-adduct of the DAGs became the precursor ion for this compound. Each precursor ion

Table 1 Source parameters of mass spectrometer

\begin{tabular}{ll}
\hline Global source settings & \\
\hline Collision gas (CAD) & Medium \\
Curtain gas (CUR) & $30 \mathrm{psi}$ \\
Nebulizer gas (GSI) & $30 \mathrm{psi}$ \\
Auxiliary gas (GS2) & $20 \mathrm{psi}$ \\
Ion spray voltage (IS) & $5500 \mathrm{~V}$ \\
Temperature (TEM) & $400^{\circ} \mathrm{C}$ \\
Entrance potential (EP) & $10 \mathrm{~V}$ \\
\hline
\end{tabular}

Table 2 Quantitative LC/MS/MS parameters for ceramide and diacylglycerol analysis

\begin{tabular}{|c|c|c|c|}
\hline Compound & Symbol & $\begin{array}{l}\text { Mass transition } \\
(\mathrm{m} / \mathrm{z})\end{array}$ & $\begin{array}{l}\text { Retention } \\
\text { time (min) } \\
\end{array}$ \\
\hline $\begin{array}{l}N \text {-palmitoyl- } \\
\text { sphingosine }\end{array}$ & $\mathrm{C} 16: 0$ & $\begin{array}{l}538.60-264.30 \\
538.60-520.60\end{array}$ & 7.2 \\
\hline $\begin{array}{l}N \text {-heptadecanoyl- } \\
\text { sphingosine }\end{array}$ & $\mathrm{C} 17: 0$ & $\begin{array}{l}552.61-264.30 \\
552.61-534.60\end{array}$ & 8.0 \\
\hline$N$-stearoyl-sphingosine & $\mathrm{C} 18: 0$ & $\begin{array}{l}566.52-264.30 \\
566.52-548.60\end{array}$ & 8.8 \\
\hline$N$-oleoyl-sphingosine & $\mathrm{C} 18: 1$ & $\begin{array}{l}564.66-264.30 \\
564.66-546.50\end{array}$ & 6.5 \\
\hline Dipalmitoyl-glycerol & $16: 0-16: 0$ & $\begin{array}{l}586.50-313.30 \\
586.50-551.50\end{array}$ & 10.2 \\
\hline $\begin{array}{l}\text { Palmitoyl-palmitoleoyl- } \\
\text { glycerol }\end{array}$ & $16: 0-16: 1$ & $\begin{array}{l}584.50-311.30 \\
584.50-313.30\end{array}$ & 9.1 \\
\hline $\begin{array}{l}\text { Palmitoyl-stearoyl- } \\
\text { glycerol }\end{array}$ & $16: 0-18: 0$ & $\begin{array}{l}614.60-313.30 \\
614.60-341.30\end{array}$ & 11.7 \\
\hline $\begin{array}{l}\text { Palmitoyl-oleoyl- } \\
\text { glycerol }\end{array}$ & $16: 0-18: 1$ & $\begin{array}{l}612.50-313.30 \\
612.50-339.30\end{array}$ & 10.7 \\
\hline $\begin{array}{l}\text { Palmitoleoyl-oleoyl- } \\
\text { glycerol }\end{array}$ & $16: 1-18: 1$ & $\begin{array}{l}610.50-311.30 \\
610.50-339.30\end{array}$ & 9.9 \\
\hline Distearoyl-glycerol & 18:0-18:0 & $\begin{array}{l}642.60-341.30 \\
642.60-607.60\end{array}$ & 12.9 \\
\hline $\begin{array}{l}\text { Stearoyl-oleoyl- } \\
\text { glycerol }\end{array}$ & $18: 0-18: 1$ & $\begin{array}{l}640.60-339.30 \\
640.60-341.30\end{array}$ & 12.0 \\
\hline Dioleoyl-glycerol & $18: 1-18: 1$ & $638.80-339.30$ & 11.4 \\
\hline
\end{tabular}

was separated in the first quadrupole (Q1), fragmented in the second quadrupole (Q2), and the product ions were scanned in the third quadrupole (Q3). We found that, as reported before $[20,22,25,32]$, one typical fragment for ceramides is the $\mathrm{m} / \mathrm{z} 264$. This is generated with the loss of the acyl group and two molecules of water. (Fig. 3). The other chosen transition was produced with the loss of one molecule of water from the precursor ion.

Fatty acid synthase enzyme yields palmitic acid (16:0) as the major primary intermediate of de novo FA synthesis in human cells. Palmitic acid can be elongated by two-carbon units and/or desaturated by enzyme systems in the ER membrane, thus it serves as the precursor of all other endogenous FAs. We aimed to determine the levels of those DAGs that contain the most abundant endogenous FAs of human cells, such as palmitic (16:0), stearic (18:0), palmitoleic (16:1 cis $\Delta 9)$ and oleic (18:1 cis $\Delta 9)$ acids in various combinations. In case of DAGs, we decided to use the ammonium-adduct as a precursor ion for each DAG, and the two daughter ions were generated with the loss of the ammonia and one of the FA chain (Fig. 4). For those DAGs, which contained two identical FAs, the other daughter ion was produced from the precursor ion with the loss of the ammonia and one molecule of water. Among the biologically relevant DAGs having two identical FA chains, the 


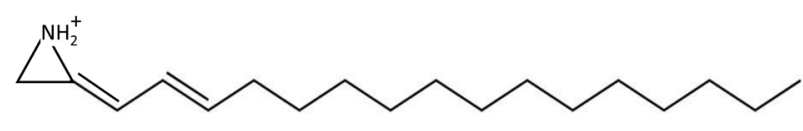

Fig. 3 Typical fragment ion of $\mathrm{m} / \mathrm{z}=264$ of ceramides generated upon positive ESI ionization

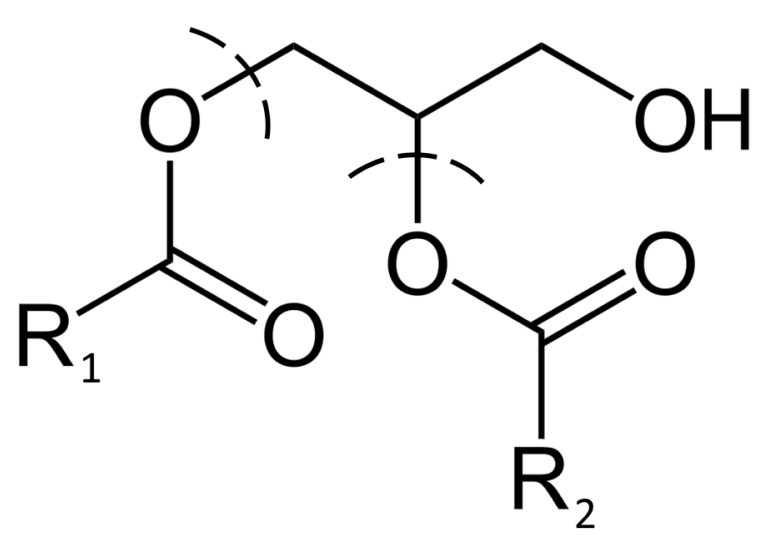

Fig. 4 Fragmentation of diacylglycerols with the loss of one fatty acid chain

second transition of only dioleoyl-glycerol (18:118:1) cannot be used because it yields ions of the same $\mathrm{m} / \mathrm{z}$ as the ones produced from the 18:018:2 DAG, so in this case, only one transition, the $638.6 \rightarrow 339.3$ was used.

\subsection{Liquid chromatography}

Fig. 5 shows a typical chromatogram of ceramides and DAGs of a control sample of the cell culture. Although in some cases, there is no baseline separation between the investigated compounds, with the MRM mode we can perform the specific identification of coeluting ceramides and DAGs. By using this gradient method, we were able to separate four ceramides and eight DAGs during a 14 min run.

\subsection{Sample preparation}

A chloroform/methanol (1:2 v/v) mixture is often used for the extraction of ceramides. However, the loss during sample drying is intolerable when studying cultured cells, due to very small amount of the samples, and carcinogenic properties of chloroform are well-known, and hence, we decided to use chloroform-free methanol for extraction. Therefore, we studied the difference between the following two extraction methods using either pure methanol or a chloroform/methanol mixture. For extraction with methanol only, washed cells were suspended in methanol, sonicated for 15-20 sec, and then centrifuged at $13400 \mathrm{rpm}$ for 10 minutes. The supernatant was directly injected from HPLC vials. For extraction with a chloroform/methanol mixture, $45 \mu \mathrm{l}$ of chloroform was added to $90 \mu \mathrm{l}$ of cell
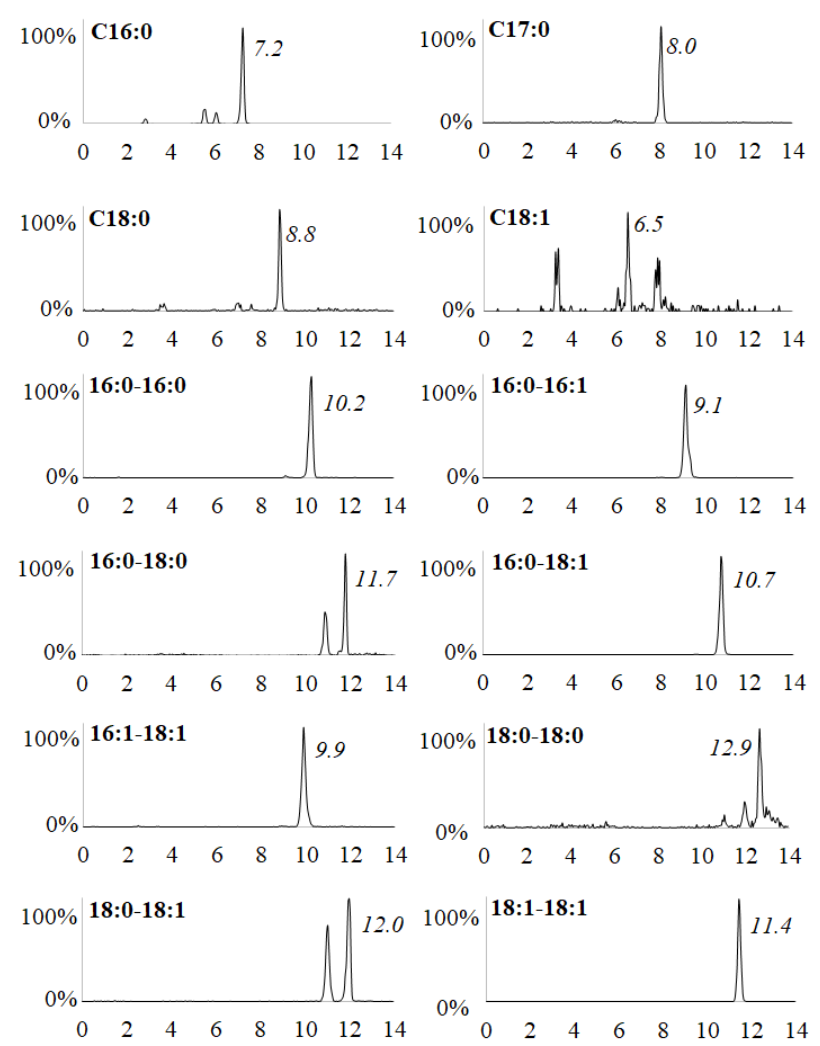

Fig. 5 Typical chromatograms of a control cell sample containing the measured ceramides and diacylglycerols. With the MRM mode, the specific identification of coeluting compounds can be achieved

suspension in methanol. The samples were sonicated and centrifuged as above. The supernatant was then dried and reconstituted in $90 \mu 1$ of methanol. The solutions were sonicated for 15-20 sec and centrifuged again, and the supernatants were transferred to HPLC vials for measurement. We found no difference between the results obtained with two methods (Fig. 6); therefore, to save time and samples, ceramides and DAGs were extracted with methanol only in the subsequent measurements.

Two different approaches were used to normalize the measured amount of ceramides and DAGs. One was based on the measurement of wet cell mass, i.e. all of the supernatant was removed from the washed cell pellets, and the volume of methanol in which the cells were suspended was proportional to the pellets' weight. The other approach was based on the measurement of protein content, i.e. $15 \mu \mathrm{l}$ of each cell suspension in PBS was withdrawn before pelleting the cells to determine the protein concentration, and the amount of methanol for suspension of the pellet was constant. The lipid concentrations were normalized to the protein concentration of the same sample. Since the first method did not yield precise and reliable results, all data were normalized to protein contents in the subsequent experiments. 

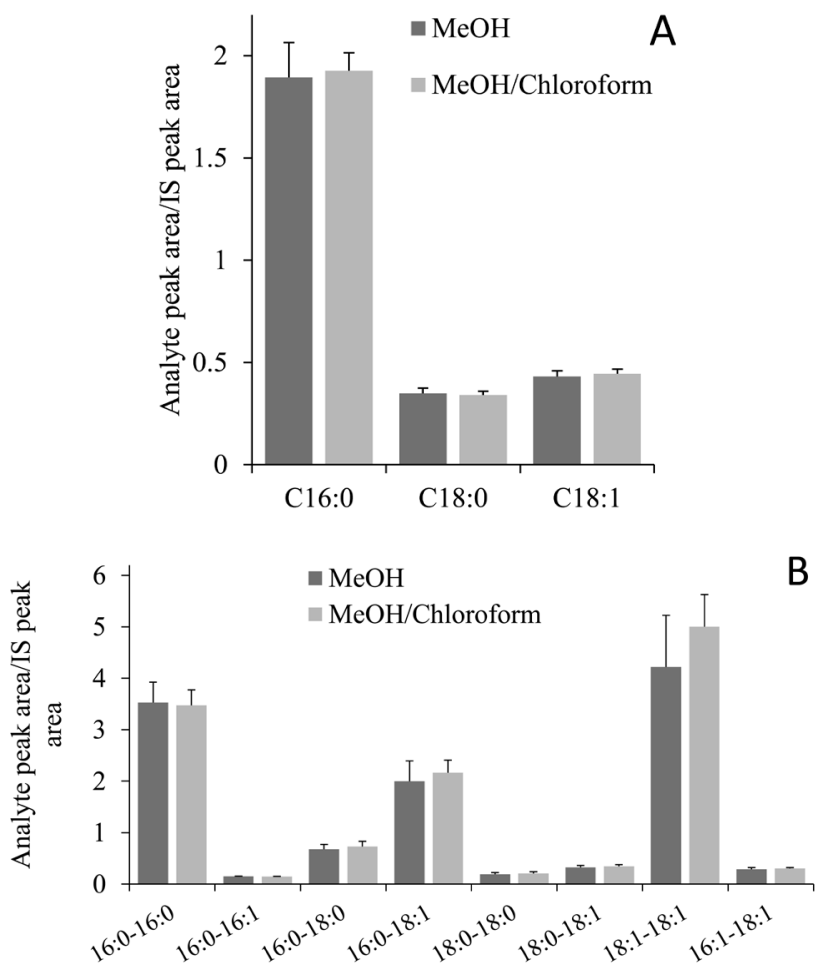

Fig. 6 Comparison of the different extraction methods. MeOH: Washed cells were suspended in methanol, sonicated for 15-20 sec, and then centrifuged at $13400 \mathrm{rpm}$ for 10 minutes. The supernatant was directly injected from HPLC vials. MeOH/chloroform: $45 \mu 1$ chloroform was added to $90 \mu \mathrm{l}$ cell suspension in methanol. The samples were sonicated and centrifuged as above. The supernatant was then dried, reconstituted in $90 \mu 1$ methanol, sonicated, centrifuged, and the supernatants were transferred to vials for HPLC analysis. Relative ceramide (A) and DAG (B) peak areas compared to the internal standard peak area are presented as mean values \pm S.D.; $n=10$.

The percentage of ceramide and DAG recovery was measured by adding known amount of ceramides and DAGs to pooled cell suspension. Recovery was between $79.1 \%$ and $86.4 \%$.

\subsection{Effect of palmitate treatment on ceramide and DAG levels in HepG2 cells}

After optimizing the sample preparation steps, we treated the cells with BSA-conjugated palmitate at a concentration of $250 \mu \mathrm{M}$ for 8 hours, and prepared samples from the collected cells as described.

Our results show an obvious accumulation of several palmitate derivatives. We observed an approximately 5-fold elevation in the level of C16:0 ceramide $(0.192 \pm 0.026$ vs $0.976 \pm 0.232 \mu \mathrm{g} / \mathrm{mg}$ protein in control vs palmitate-treated, respectively) and a 5.5-fold elevation in the level of $\mathrm{C} 18: 0$ ceramide $(0.0153 \pm 0.004$ vs $0.086 \pm 0.015 \mu \mathrm{g} / \mathrm{mg}$ protein in control vs palmitate-treated, respectively) (Fig. 7). The C18:0 ceramide contains a stearoyl chain, which is produced in the cells by the elongation of palmitate.

A significant elevation was found in the amount of different DAGs as well (Fig. 8), especially in the dipalmitoyl-glycerol (16:0-16:0) (18.5-fold, $0.71 \pm 0.233$ vs $13.08 \pm 2.914 \mu \mathrm{g} /$ $\mathrm{mg}$ protein in control vs palmitate-treated, respectively) the palmitoyl-palmitoleoyl-glycerol (16:0-16:1) (8-fold, $0.36 \pm 0.059$ vs $2.96 \pm 0.389 \mu \mathrm{g} / \mathrm{mg}$ protein in control and palmitate-treated, respectively) and palmitoyl-stearoyl-glycerol (16:0-18:0) (6.5-fold, $0.12 \pm 0.054$ vs $0.77 \pm 0.214 \mu \mathrm{g} / \mathrm{mg}$ protein in control vs palmitate-treated, respectively) levels.

The ratio of fully saturated DAGs (i.e. containing saturated FAs only) and partly or fully unsaturated ones (i.e. having at least one unsaturated FA chain) changed remarkably, from 0.11 to 0.82 upon palmitate treatment (Fig. 9).

\section{Discussion}

The role of ceramides and DAGs in a variety of pathological conditions has attracted a growing attention in the last few years. Excessive FA supply, which occurs in high-fat diet and in obesity, causes an elevation of intracellular acylCoA levels and thus stimulates several acylation reactions involved in the biosynthesis of complex lipids. Acceleration of sphingosine $N$-acylation produces ceramides, which are known to trigger ER stress, insulin resistance and apoptosis in various cell lines. Enhanced acylations also lead to

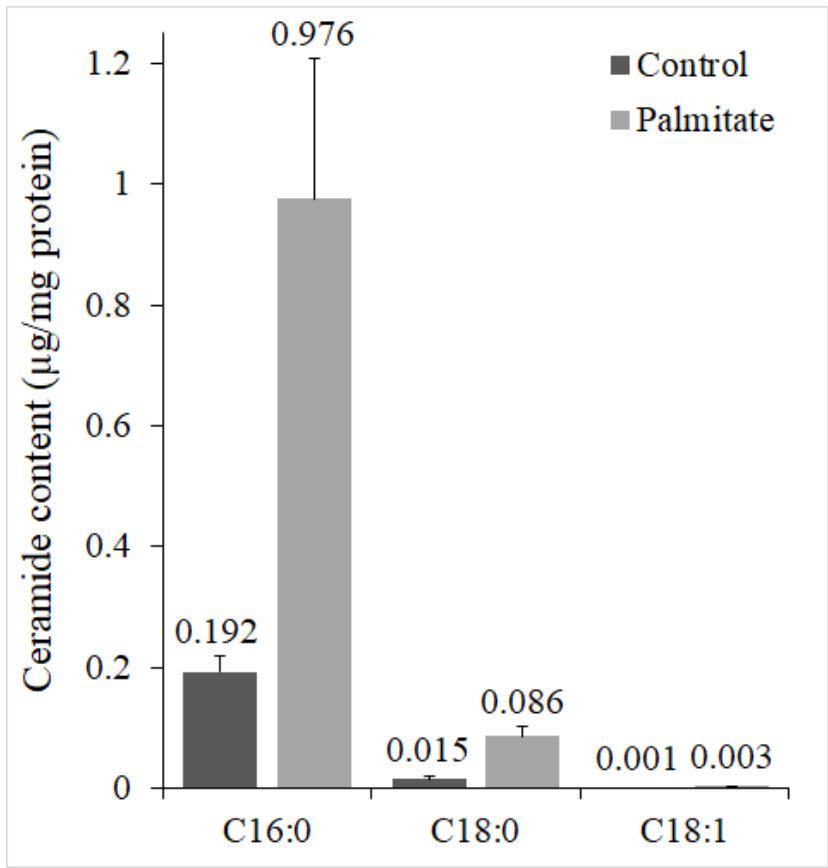

Fig. 7 Effect of palmitate treatment on ceramide levels. Cells were treated with BSA (control) or BSA-conjugated palmitate $(250 \mu \mathrm{M})$ at $70-80 \%$ confluence for $8 \mathrm{~h}$. Ceramide levels were measured by LC-MS/MS and normalized to $1 \mathrm{mg}$ protein. Data are shown as means \pm S.D.; $\mathrm{n}=10$. 


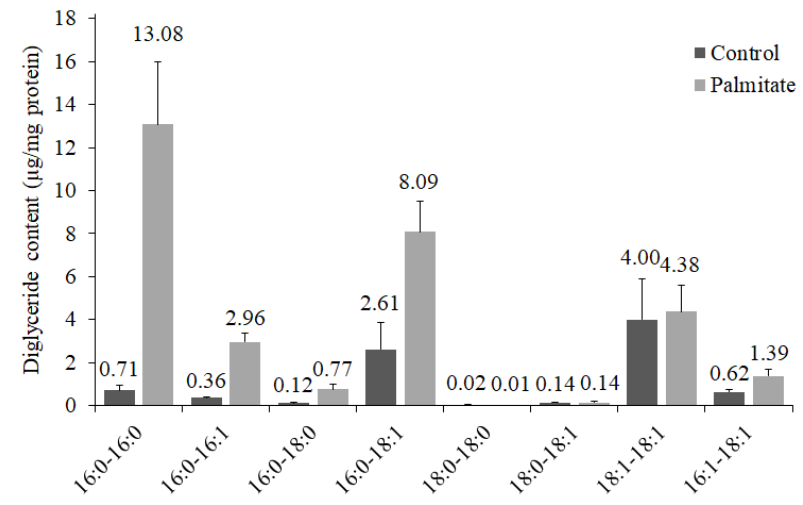

Fig. 8 Effect of palmitate treatment on diacylglycerol levels. Cells were treated with BSA (control) or BSA-conjugated palmitate $(250 \mu \mathrm{M})$ at $70-80 \%$ confluence for $8 \mathrm{~h}$. Diacylglycerol levels were measured by LCMS/MS normalized to $1 \mathrm{mg}$ protein. Data are mean values \pm S.D.; $\mathrm{n}=10$.
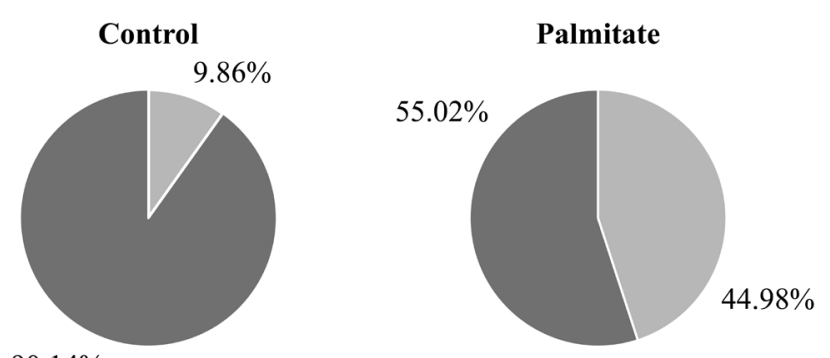

$90.14 \%$

Fully saturated DAGs Unsaturated DAGs

Fig. 9 Alteration in the ratio of fully saturated and at least partly unsaturated diacylglycerols upon palmitate treatment. Cells were treated with BSA (control) or BSA-conjugated palmitate $(250 \mu \mathrm{M})$ at $70-80 \%$ confluence for $8 \mathrm{~h}$. The amounts of saturated (16:016:0, 16:018:0, 18:018:0) and at least partly unsaturated (16:016:1, 16:018:1, 16:118:1, 18:018:1, 18:118:1, 16:1-18:1) DAGs were measured by LC-MS/MS.

the production of triglycerides, and deposition of fat droplets is an obvious sign of lipotoxicity. It has been revealed, however, that obstruction of triglyceride synthesis before the final step, and the consequent accumulation of DAGs is especially deleterious because it activates different members of the protein kinase C (PKC) family, and hence contributes to stress and insulin resistance. Therefore, an increasing number of cellular and in vivo studies aim to monitor the intracellular levels of ceramides and DAGs along with alterations in cellular functions and development of characteristic pathological conditions.

Its high selectivity, sensitivity and accuracy make HPLC-ESI-MS/MS technique suitable for efficient and precise quantitative analysis of various cellular compounds of low molecular weight and of similar structures in biological matrices [33]. Here, we demonstrate the development of a reverse-phased HPLC-ESI-MS/MS method for the simultaneous determination of a wide range of ceramides and DAGs in cultured cells. A non-physiological C17:0 ceramide containing a fatty acyl chain of odd number of carbons, which cannot be produced in mammalian cells, was used as an internal standard in our methodology. The lipid species were separated from the impurities by liquid chromatography, and multiple reaction monitoring mode enabled the identification of coeluting components. Regarding the sample preparation, most of the experiments refer to the method reported by Bligh and Dyer [34] which uses a chloroform-methanol mixture to extract and purify lipids from biological samples. However, we demonstrate here, that the use of methanol alone provides the same yield in one step without a time-consuming extraction protocol in case of ceramides and DAGs.

Our experiments on palmitate-treated cultured cells clearly show the accumulation of lipid-intermediates. In case of ceramides, the increasing levels have two explanations. On one hand, the oversupply of palmitoyl-CoA induces the synthesis of sphinganine, which can react with another acyl-CoA in the acylation catalyzed by the ceramide synthase. Elongation of a palmitoyl-CoA yields stearoyl-CoA, which can give rise to the C18:0 ceramide. On the other hand, acylation of sphingosine, an intermediate of sphingolipid breakdown also produces ceramides in the salvage pathway. Manukyan et al. [35] used two different enzyme inhibitors, a serine palmitoyl transferase and a ceramide synthase inhibitor, to determine whether it is the de novo synthesis or the salvage pathway that plays the primary role in the accumulation of ceramides during prolonged exposure to FAs. Their results suggest that the de novo synthesis and the salvage pathway contributes equally to the increased ceramide levels.

In case of DAGs in palmitate treated cells, we found significantly elevated levels of all examined DAGs except the palmitoleoyl-oleoyl-glycerol and dioleoyl-glycerol. Interestingly, we observed a 17 -fold elevation in the total level of DAGs containing two saturated fatty acyl chains. The synthesis of triglycerides follows a genetically determined pattern. Normally, a saturated fatty acyl group occupies the first position of glycerol and an unsaturated fatty acyl group is attached in the second position [36]. This may suggest that the further acylation of the fully saturated DAGs may stall. Moreover, since DAGs are precursors of phospholipids, their structure has direct effects on the composition of the membrane lipids. The increased level of saturation of membrane lipids has been reported to trigger the ER stress $[4,5]$, which in turn may cause cell death, fibrosis and inflammation. 


\section{Acknowledgement}

We thank Ms. Valéria Mile for skillful technical assistance. This work was supported by the Hungarian National Research, Development and Innovation Office (NKFIH grant number: K 125201) and by the Higher Education Excellence Program of the Ministry of Human Capacities

\section{References}

[1] Gershuni, V. M. "Saturated Fat: Part of a Healthy Diet", Current Nutrition Reports, 7(3), pp. 85-96, 2018.

https://oi.org/10.1007/s13668-018-0238-x

[2] El Kady, S. A., Abd El Gawwad, A. I., Kassem, A. E., Hamed, M. I., Rabie, M. M., Lásztity, R. "Effect of Different Alkali Concentrations during the Refining Process on the Fatty Acid Composition of Sunflower and Soybean oils", Periodica Polytechnica Chemical Engineering, 37(3-4), pp. 147-152, 1993.

[3] Dhaygude, V., Soós, A., Somogyi, L. "Solidification of the Blends of Fully Hydrogenated Coconut Oil and Non-hydrogenated Coconut Oil", Periodica Polytechnica Chemical Engineering, 62(1), pp. 123-127, 2018. https://doi.org/10.3311/PPch.9638

[4] Zámbó, V., Simon-Szabó, L., Szelényi, P., Kereszturi, É., Bánhegyi, G., Csala, M. "Lipotoxicity in the liver", World Journal of Hepatology, 5(10), pp. 550-557, 2013. https://doi.org/10.4254/wjh.v5.110.550

[5] Mand1, J., Mészáros, T., Bánhegyi, G., Csala, M. "Minireview: Endoplasmic Reticulum Stress: Control in Protein, Lipid, and Signal Homeostasis", Molecular Endocrinology, 27(3), pp. 384-393, 2013. https://doi.org/10.1210/me.2012-1317

[6] Jayadev, S., Liu, B., Bielawska, A. E., Lee, J. Y., Nazaire, F., Pushkareva, M. Yu., Obeid, L. M., Hannun, Y. A. "Role for Ceramide in Cell Cycle Arrest", The Journal of Biological Chemistry, 270(5), pp. 2047-2052, 1995.

https://doi.org/10.1074/jbc.270.5.2047

[7] Venable, M. E., Lee, J. Y., Smyth, M. J., Bielawska, A., Obeid, L. M. "Role of Ceramide in Cellular Senescence", The Journal of Biological Chemistry, 270(51), pp. 30701-30708, 1995. https://doi.org/10.1074/jbc.270.51.30701

[8] Shimabukuro, M., Zhou, Y. T., Levi, M., Unger, R. H. "Fatty acid-induced $\beta$ cell apoptosis: A link between obesity and diabetes", Proceedings of the National Academy of Sciences of the United States of America, 95(5), pp. 2498-2502, 1998. https://doi.org/10.1073/pnas.95.5.2498

[9] Zhu, Q., Yang, J., Zhu, R., Jiang, X., Li, W., He, S., Jin, J. "Dihydroceramide-desaturase-1-mediated caspase 9 activation through ceramide plays a pivotal role in palmitic acid-induced HepG2 cell apoptosis", Apoptosis, 21(9), pp. 1033-1044, 2016. https://doi.org/10.1007/s10495-016-1267-9

[10] Galadari, S., Rahman, A., Pallichankandy, S., Galadari, A., Thayyullathil, F. "Role of ceramide in diabetes mellitus: evidence and mechanisms", Lipids in Health and Disease, 12(1), Article Number: 98, 2013.

https://doi.org/10.1186/1476-511X-12-98 in the frame of Biotechnology research area of Budapest University of Technology and Economics (BME FIKPBIO). Anna Somogyi is a grantee of the ÚNKP-19-3I-SE-86 New National Excellence Program of the Ministry for Innovation and Technology.

[11] Watson, S. P., Lapetina, E. G. "1,2-Diacylglycerol and phorbol ester inhibit agonist-induced formation of inositol phosphates in human platelets: possible implications for negative feedback regulation of inositol phospholipid hydrolysis", Proceedings of the National Academy of Sciences of the United States of America, 82(9), pp. 2623-2626, 1985.

https://doi.org/10.1073/pnas.82.9.2623

[12] Moore, P. C., Ugas, M. A., Hagman, D. K., Parazzoli, S. D., Poitout, V. "Evidence Against the Involvement of Oxidative Stress in Fatty Acid Inhibition of Insulin Secretion", Diabetes, 53(10), pp. 2610-2616, 2004.

https://doi.org/10.2337/diabetes.53.10.2610

[13] Preiss, J. E., Loomis, C. R., Bell, R. M., Niedel, J. E. "Quantitative Measurement of sn-1,2-diacylglycerols", Methods in Enzymology, 141, pp. 294-300, 1987. https://doi.org/10.1016/0076-6879(87)41077-x

[14] Van Veldhoven, P. P., Bishop, W. R., Yurivich, D. A., Bell, R. M. "Ceramide Quantitation: Evaluation of a Mixed Micellar Assay Using E. Coli Diacylglycerol Kinase", Biochemistry and Molecular Biology International, 36(1), pp. 21-30, 1995.

[15] Tepper, A. D., Boesen-de Cock, J. G. R., de Vries, E., Borst, J., van Blitterswijk, W. J. "CD95/Fas-induced Ceramide Formation Proceeds with Slow Kinetics and Is Not Blocked by Caspase-3/ CPP32 Inhibition", The Journal of Biological Chemistry, 272(39), pp. 24308-24312, 1997. https://doi.org/10.1074/jbc.272.39.24308

[16] Okumura, K., Hayashi, K., Morishima, I., Murase, K., Matsui, H., Toki, Y., Ito, T. "Simultaneous quantitation of ceramides and 1,2-diacylglycerol in tissues by latroscan thin-layer chromatography-flame-ionization detection", Lipids, 33(5), pp. 529-532, 1998. https://doi.org/10.1007/s11745-998-0237-3

[17] Iwamori, M., Costello, C., Moser, H. W. "Analysis and quantitation of free ceramide containing nonhydroxy and 2-hydroxy fatty acids, and phytosphingosine by high-performance liquid chromatography", Journal of Lipid Research, 20(1), pp. 86-96, 1979.

[18] Previati, M., Bertolaso, L., Tramarin, M., Bertagnolo, V., Capitani, S. "Low Nanogram Range Quantitation of Diglycerides and Ceramide by High-Performance Liquid Chromatography", Analytical Biochemistry, 233(1), pp. 108-114, 1996. https://doi.org/10.1006/abio.1996.0014

[19] Garzotto, M., White-Jones, M., Jiang, Y., Ehleiter, D., Liao, W. C., Haimovitz-Friedman, A., Fuks, Z., Kolesnick, R. "12-O-tetradecanoylphorbol-13-acetate-induced apoptosis in LNCaP cells is mediated through ceramide synthase", Cancer Research, 58(10), pp. 2260-2264, 1998. 
[20] Liebisch, G., Drobnik, W., Reil, M., Trümbach, B., Arnecke, R., Olgemöller, B., Roscher, A., Schmitz, G. "Quantitative Measurement of Different Ceramide Species From Crude Cellular Extracts by Electrospray Ionization Tandem Mass Spectrometry (ESI-MS/ MS)", Journal of Lipid Research, 40(8), pp. 1539-1546, 1999.

[21] Han, X. "Characterization and Direct Quantitation of Ceramide Molecular Species from Lipid Extracts of Biological Samples by Electrospray Ionization Tandem Mass Spectrometry", Analytical Biochemistry, 302(2), pp. 199-212, 2002.

https://doi.org/10.1006/abio.2001.5536

[22] Chen, J., Narayan, S. B., Edinger, A. L., Bennett, M. J. "Flow injection tandem mass spectrometric measurement of ceramides of multiple chain lengths in biological samples", Journal of Chromatography B, 883-884, pp. 136-140, 2012. https://doi.org/10.1016/j.jchromb.2011.11.017

[23] Mano, N., Oda, Y., Yamada, K., Asakawa, N., Katayama, K. "Simultaneous Quantitative Determination Method for Sphingolipid Metabolites by Liquid Chromatography/Ionspray Ionization Tandem Mass Spectrometry", Analytical Biochemistry, 244(2), pp. 291-300, 1997.

https://doi.org/10.1006/abio.1996.9891

[24] Bielawski, J., Szulc, Z. M., Hannun, Y. A., Bielawska, A. "Simultaneous quantitative analysis of bioactive sphingolipids by high-performance liquid chromatography-tandem mass spectrometry", Methods, 39(2), pp. 82-91, 2006.

https://doi.org/10.1016/j.ymeth.2006.05.004

[25] Kasumov, T., Huang, H., Chung, Y. M., Zhang, R., McCullough, A. J., Kirwan, J. P. "Quantification of ceramide species in biological samples by liquid chromatography electrospray ionization tandem mass spectrometry", Analytical Biochemistry, 401(1), pp. 154-161, 2010. https://doi.org/10.1016/j.ab.2010.02.023

[26] Chuang, W. L., Pacheco, J., Zhang, K. "A Simple, HighThroughput Method for Analysis of Ceramide, Glucosylceramide, and Ceramide Trihexoside in Dried Blood Spots by LC/MS/MS", In: Garg, U. (ed.) Clinical Applications of Mass Spectrometry in Biomolecular Analysis: Methods in Molecular Biology, Humana Press, New York, NY, USA, 2016, pp. 263-272. https://doi.org/10.1007/978-1-4939-3182-8_28

[27] Brüschweiler, H., Dieffenbacher, A. "Determination of Monoand Diglycerides by Capillary Gas Chromatography", Pure and Applied Chemistry, 63(8), pp. 1153-1162, 1991

[28] Leiker, T. J., Barkley, R. M., Murphy, R. C. "Analysis of diacylglycerol molecular species in cellular lipid extracts by normal-phase LC-electrospray mass spectrometry", International Journal of Mass Spectrometry, 305(2-3), pp. 103-108, 2011. https://doi.org/10.1016/j.ijms.2010.09.008
[29] Callender, H. L., Forrester, J. S., Ivanova, P., Preininger, A., Milne, S., Brown, H. A. "Quantification of Diacylglycerol Species from Cellular Extracts by Electrospray Ionization Mass Spectrometry Using a Linear Regression Algorithm", Analytical Chemistry, 79(1), pp. 263-272, 2007.

https://oi.org/10.1021/ac061083q

[30] Li, Y. L., Su, X., Stahl, P. D., Gross, M. L. "Quantification of Diacylglycerol Molecular Species in Biological Samples by Electrospray Ionization Mass Spectrometry after One-Step Derivatization", Analytical Chemistry, 79(4), pp. 1569-1574, 2007. https://doi.org/10.1021/ac0615910

[31] Simon-Szabó, L., Kokas, M., Mandl, J., Kéri, G., Csala, M. "Metformin Attenuates Palmitate-Induced Endoplasmic Reticulum Stress, Serine Phosphorylation of IRS-1 and Apoptosis in Rat Insulinoma Cells", PLoS One, 9(6), Article Number: e97868, 2014. https://doi.org/10.1371/journal.pone.0097868

[32] Gu, M., Kerwin, J. L., Watts, J. D., Aebersold, R. "Ceramide Profiling of Complex Lipid Mixtures by Electrospray Ionization Mass Spectrometry", Analytical Biochemistry, 244(2), pp. 347-356, 1997. https://doi.org/10.1006/abio.1996.9915

[33] Somogyi, A., Horvai, G., Csala, M., Tóth, B. "Analytical Approaches for the Quantitation of Redox-active Pyridine Dinucleotides in Biological Matrices", Periodica Polytechnica Chemical Engineering, 60(4), pp. 218-230, 2016. https://doi.org/10.3311/PPch.9470

[34] Bligh, E. G., Dyer, W. J. "A Rapid Method of Total Lipid Extraction and Purification", Canadian Journal of Biochemistry and Physiology, 37(8), pp. 911-917, 1959. https://doi.org/10.1139/y59-099

[35] Manukyan, L., Ubhayasekera, S. J. K. A., Bergquist, J., Sargsyan, E., Bergsten, P. "Palmitate-Induced Impairments of $\beta$-cell Function Are Linked With Generation of Specific Ceramide Species via Acylation of Sphingosine", Endocrinology, 156(3), pp. 802-812, 2015. https://doi.org/10.1210/en.2014-1467

[36] Yamashita, A., Hayashi, Y., Nemoto-Sasaki, Y., Ito, M., Oka, S., Tanikawa, T., Waku, K., Sugiura, T. "Acyltransferases and transacylases that determine the fatty acid composition of glycerolipids and the metabolism of bioactive lipid mediators in mammalian cells and model organisms", Progress in Lipid Research, 53, pp. 18-81, 2014. https://doi.org/10.1016/j.plipres.2013.10.001 